\title{
Study on Recycled Polystyrene Plastic/SiO 2 Melting Blending Modified Nanocomposites
}

\author{
Chen Jie, Li Dao-hua*, He Shao-fen, Jiang Cheng-yan and Li Zong-yi \\ College of Chemistry and Chemical Engineering, Neijiang Normal University, \\ Neijiang 641112, China \\ chenj@163.com, daohl@163.com, hesf@163.com, jiangcy@163.com, lizy@163.com
}

\begin{abstract}
Keywords: Recycled polystyrene(PS); Nano-SiO ${ }_{2}$; Melting blending modified; Nanocomposites; Mechanical properties; Structure characterization

Abstract. The addition of nano- $\mathrm{SiO}_{2}$ to $20 \%$ silane coupling agent is carried out using anhydrous ethanol as the solvent in the presence of acetic acid. The styrene-butadiene-styrene (SBS) is added with $1 \%$ dicumyl peroxide crosslinking agent by adding $5 \%$ maleic anhydride grafted polyethylene to be modified on an extruder. Polystyrene/nano- $\mathrm{SiO}_{2}$ composites are prepared by blending nano-SiO 2 and SBS in different proportions with waste polystyrene. Three mechanical properties of the newly prepared materials are tested, including the tensile strength, impact strength, and flexural strength. The results show that the composite properties of polystyrene/nano- $\mathrm{SiO}_{2}$ composites containing $8 \%$ nano- $\mathrm{SiO}_{2}$ are the best. The microstructures and physicochemical structures of the composites were further studied by means of infrared spectroscopy (FT-IR), X ray diffraction (XRD), scanning electron microscopy (SEM) and thermogravimetric-differential thermal analysis (TG-DTA). The results reveal that the tensile, impact and bending properties of $8 \%$ nano- $\mathrm{SiO}_{2}$ composites are improved best, and at the same time, the proportion of the prepared composite structure is stable. The preparation method of the composite material is simple and easy to operate, and has certain industrial application prospect.
\end{abstract}

\section{Introduction}

Polystyrene (PS) plastic is widely used in household appliances, instrumentation, toys, advertising decoration, insulation and packaging materials, resulting in a large amount of waste PS plastic[1, 2]. At present, the main method of dealing with waste PS plastic is used to produce polystyrene waterproof and waterproof coating, protective paint, adhesive and other products, using a small amount of organic solvent will be difficult to recover the waste polystyrene foam dissolved and precipitated after filtration, then add some additives made of paint, protective paint or adhesive[3, 4]. As a result of waste utilization, cost reduction, there are certain economic and social benefits. If the waste polystyrene foam is not comprehensively recycled, then it is not only a great waste of resources but also a great deal of pollution to the environment $[5,6]$.

This paper studies the preparation of modified nanocomposites with recycling of waste PS plastic, where its formula design and process flow are considered[7, 8]. It uses the recycled recycling of waste PS plastic as the main body of the resin and nano- $\mathrm{SiO}_{2}$ nanomaterial as the filler, which form the mixed material with dibutyl phthalate (DPB), ordinary paraffin, antioxidant 1010, silane coupling agent (KH-550), dicumyl peroxide (DCP), composite anti-aging agent, and carbon black. The mechanical properties of the product are tested and its structure is characterized by using XRD, FT-IR, TG-DTA and SEM. Moreover, the different percentages of fillers, interface agents, coupling agents and lotion are studied in the experiment, which reveals the application performance and preparation mechanism $[9,10]$.

\section{Experimental}

Pretreatment recycled of waste PS plastic 
Add $5 \mathrm{~g}$ of sodium xylene sulfonate, $10 \mathrm{~g}$ of sodium bicarbonate, and $3 \mathrm{~g}$ of calcium chloride into $980 \mathrm{~mL}$ of distilled water, and prepare the mixture as a homogeneous cleaning solution. Then, put the waste PS plastic into the cleaning solution and stir for 5 8 min. During this time, add appropriate $\mathrm{NaHCO}_{3}$ solid to make the $\mathrm{pH}$ remain around 9 and to remove the remaining drugs on the plastic. After that, place the washed plastic into the oven and set the drying temperature as $60{ }^{\circ} \mathrm{C}$. At last, carry out the small iron scrap adsorption experiment to the dried waste PS plastic comprehensively with the magnetic tool, which helps avoid damage to the injection molding machine.

Modification of nano- $\mathrm{SiO}_{2}$

The nano- $\mathrm{SiO}_{2}$ powder is dried in a vacuum oven at $100{ }^{\circ} \mathrm{C}$ for 24 hours. After drying the $\mathrm{SiO}_{2}$ in a beaker, the $\mathrm{SiO}_{2}$ and some silane coupling agent KH-550 ethanol solution will be mixed in an amount ratio of 10: 1 , and the modified nano- $\mathrm{SiO}_{2}$ dispersion is obtained by stirring for about 30 minutes. The modified $\mathrm{SiO}_{2}$ is precipitated by centrifugal separation and dried in an oven at $60{ }^{\circ} \mathrm{C}$.

Silane coupling agent ethanol solution is configured as follows: Dissolve the $20 \%$ silane coupling agent with $72 \%$ absolute ethanol, and add some $8 \%$ acetic acid into the solution to adjust its $\mathrm{pH}$ to 3.5 $\sim 4.5$, where the acetic acid is used as the hydrolysis catalyst.

SBS surface modification

Weigh $298.5 \mathrm{~g}$ SBS, $1.2 \mathrm{~g}$ maleic anhydride grafted polyethylene (MAPE) and $0.3 \mathrm{~g}$ DCP crosslinking agent. First mix the MAPE and SBS evenly. Then, pour them into the funnel of the extruder feed inlet and add the DCP crosslinking agent during melt mixing. The extruded material should be cooled before cutting into granules. At last, place the granules in the blast oven for 2 hours, which results in the modified SBS for the experiment.

Preparation of recycled polystyrene/ $/ \mathrm{SiO}_{2}$ modified nanocomposites

Table 1 is the preparation formulation and composition of modified nanocomposites. Weigh the recycled of waste PS plastic and other additives according to the formula and mix them into uniformly mixed materials. After the temperature reaches the set temperature, keep the temperature constant for 10 20 min. Then, open the extruder motor and set the extrusion speed as $35 \mathrm{rpm} / \mathrm{min}$.

Table 1 Process formulation of modified nanocomposite materials with recycled polystyrene(PS) plastics

\begin{tabular}{|c|c|c|c|c|c|c|c|}
\hline \multirow[b]{2}{*}{ No } & \multirow[b]{2}{*}{ Category } & \multirow[b]{2}{*}{ Ingredients } & \multicolumn{5}{|c|}{ Sample number (quality and proportion) } \\
\hline & & & $\mathrm{A} 1 / \mathrm{g}(\%)$ & $\mathrm{A} 2 / \mathrm{g}(\%)$ & $\mathrm{A} 3 / \mathrm{g}(\%)$ & $\mathrm{A} 4 / \mathrm{g}(\%)$ & $\mathrm{A} 5 / \mathrm{g}(\%)$ \\
\hline 1 & Raw material & Recycled waste PS plastic & $680(68)$ & $660(66)$ & $640(64)$ & $620(62)$ & $600(60)$ \\
\hline 2 & Filler & Modified nano-SiO ${ }_{2}$ & $40(4)$ & $60(6)$ & $80(8)$ & $100(10)$ & $120(12)$ \\
\hline 3 & Stabilizer & Antioxidant 1010 & $2(0.2)$ & $2(0.2)$ & $2(0.2)$ & $2(0.2)$ & $2(0.2)$ \\
\hline 4 & Lubricant & Paraffin & $10(1)$ & $10(1)$ & $10(1)$ & $10(1)$ & $10(1)$ \\
\hline 5 & Toughener & Styrene-butadiene-styrene (SBS) & $100(10)$ & $100(10)$ & $100(10)$ & $100(10)$ & $100(10)$ \\
\hline 6 & Crosslinking agent & Dicumyl peroxide (DCP) & $10(1)$ & $10(1)$ & $10(1)$ & $10(1)$ & $10(1)$ \\
\hline 7 & Plasticizer & Dibutyl phthalate (DPB) & $108(10.8)$ & $108(10.8)$ & $108(10.8)$ & $108(10.8)$ & $108(10.8)$ \\
\hline 8 & Colorant & Carbon black colorant & $50(5)$ & $50(5)$ & $50(5)$ & $50(5)$ & $50(5)$ \\
\hline
\end{tabular}

Extruder temperature at different heating districts: preheat $70 \sim 80{ }^{\circ} \mathrm{C}$, district one $170 \sim 200{ }^{\circ} \mathrm{C}$, district two $160 \sim 170{ }^{\circ} \mathrm{C}$, district three $140 \sim 170{ }^{\circ} \mathrm{C}$, outlet $150 \sim 170{ }^{\circ} \mathrm{C}$. Plastic injection molding machine temperature at different heating districts: preheat $70 \sim 80{ }^{\circ} \mathrm{C}$, front section $170 \sim 200{ }^{\circ} \mathrm{C}$, middle section $160 \sim 170{ }^{\circ} \mathrm{C}$, final part $140 \sim 170{ }^{\circ} \mathrm{C}$, mold $150 \sim 170{ }^{\circ} \mathrm{C}$.

Performance testing and structural characterization

The tensile properties, impact properties and bending properties of modified nanocomposite 
materials are tested by XWW-20A universal test machine. The test results are obtained by averaging five samples. The samples are subjected to infrared spectroscopy (FT-IR) test using a TJ270-30 infrared spectrophotometer. X-ray diffraction (XRD) tests are performed on DX-2700 X-Ray. The $\mathrm{XRD}$ test is performed to adjust the control parameters, where the starting angle is $20^{\circ}$, the termination angle is $60^{\circ}$, the step angle is $0.03^{\circ}$, the sampling time is $0.5 \mathrm{~s}$, the tube voltage is $40 \mathrm{kV}$, and the tube current is $40 \mathrm{~mA}$. The samples are scanned by scanning electron microscopy (SEM) with VEA3SBH scanning electron microscopy (SEM). The samples are cross - coated by ion sputtering, and the cross-sectional morphology is observed under scanning electron microscope. The samples are subjected to differential thermal and thermogravimetric analysis (TG-DTA) test using a comprehensive thermal analyzer (HCT-3 microcomputer differential thermal balance).

\section{Results and Discussions}

Mechanical properties of modified nanocomposites

Table 2 shows the mechanical properties of waste PS plastic modified nanocomposites, and Fig. $1 \sim 3$ contain the experimental results of the tensile strength, the flexural strength and the impact strength of the modified nanocomposites separately. It can be seen from Fig.1 that when the amount of nano- $\mathrm{SiO}_{2}$ is between $4 \% \sim 8 \%$, the tensile strength of the composites increases with the addition of nano- $\mathrm{SiO}_{2}$. When the content of nano- $\mathrm{SiO}_{2}$ is more than $8 \%$, the tensile strength and elongation at break does not rise but begins to fall. When the amount of nano- $\mathrm{SiO}_{2}$ is $8 \%$, the tensile strength of polystyrene/nano- $\mathrm{SiO}_{2}$ composites is $22.52 \mathrm{MPa}$ and the elongation at break is $4.32 \%$, which is the maximum and the tensile properties of the composites are better.

Table 2 Mechanical properties of modified nano-samples from recycled polystyrene (PS) plastics

\begin{tabular}{ccccccc}
\hline No. & Sample & $\begin{array}{c}\text { Tensile Strength } \\
\text { /MPa }\end{array}$ & $\begin{array}{c}\text { Elongation at break } \\
/ \%\end{array}$ & $\begin{array}{c}\text { Impact strength } \\
\mathrm{kJ} / \mathrm{m}^{2}\end{array}$ & $\begin{array}{c}\text { Flexural strength } \\
/ \mathrm{MPa}\end{array}$ & \multicolumn{2}{c}{ Flexural modulus } \\
$/ \mathrm{MPa}$
\end{tabular}

Description: A is the waste PS plastic formula, A1 A5 are the specific implementation formulas (Table 1).

It can be seen from Fig.2, adding a certain amount of nano-SiO $\mathrm{S}_{2}$, composite bending strength and bending modulus were first increased and then decreased. When the content of nano- $\mathrm{SiO}_{2}$ is $8 \%$, the flexural strength and flexural modulus of polystyrene/nano- $\mathrm{SiO}_{2}$ composites reach the maximum, and the flexural strength is $32 \%$ higher than that of waste polystyrene, and the flexural modulus is higher than that of waste polystyrene Ethylene increased by $22 \%$. Fig.3 shows the effect of different filling mass fractions of nano- $\mathrm{SiO}_{2}$ on the impact strength of the composites. It can be observed from Fig.3 that the impact strength of the composite material increases with the increase of the nano- $\mathrm{SiO}_{2}$ content when the nano- $\mathrm{SiO}_{2}$ content is less than $8 \%$. When the mass fraction is $8 \%$, the maximum value is $18.33 \mathrm{~kJ} / \mathrm{m}^{2}$, and the toughening effect is improved, but it is not obvious. When the mass fraction of $\mathrm{SiO}_{2}$ exceeds $8 \%$, the impact strength of the composites decreases with the increase of the mass fraction of nano- $\mathrm{SiO}_{2}$.

Infrared spectroscopy (FT-IR) analysis of modified nanocomposites

Fig. 4 for the waste polystyrene and adding $8 \%$ nano-silica composite infrared spectrum, the number of waves in the figure between $1500 \sim 1600$ nanocomposite spectra have obvious characteristics of the peak, while the waste polystyrene plastic did not. It is found that the 
characteristic peaks of $\mathrm{Si}-\mathrm{O}$ bonds are between $1500 \sim 1600$, indicating the presence of uniformly dispersed nano-SiO $\mathrm{Sin}_{2}$ in nanocomposites. It can be seen from Figure 5 that the peaks of the nanocomposites are stronger than those of the used polystyrene plastic, indicating that the performance of the nanocomposites is enhanced. In the infrared spectrum, we found that the lower (higher) the transmittance, the higher (lower) the peak. Since the infrared spectrum characterizes the group in the composite, and the infrared spectroscopy is sensitive to the inorganic, while the peaks of the organic matter are not so obvious, the peaks in the figure are strong and obvious, which indicates that the nanoparticles and other inorganic additives are attached to the composite.

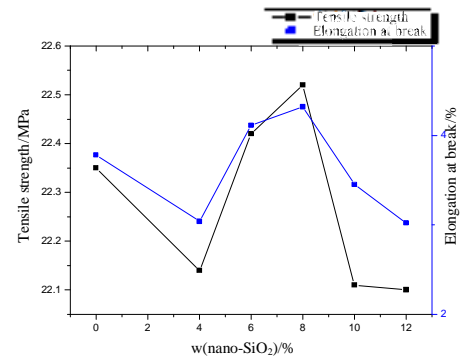

Fig.1 Effect of nano-SiO ${ }_{2}$ content on tensile strength and elongation at break of composite

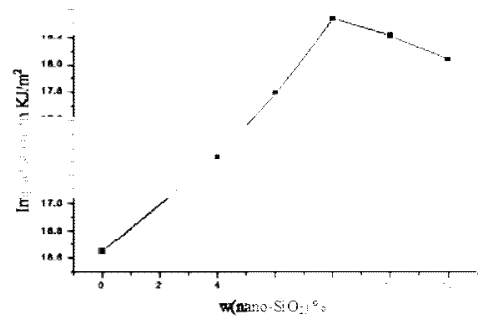

Fig.3 Effect of nano- $\mathrm{SiO}_{2}$ content on impact strength of composite

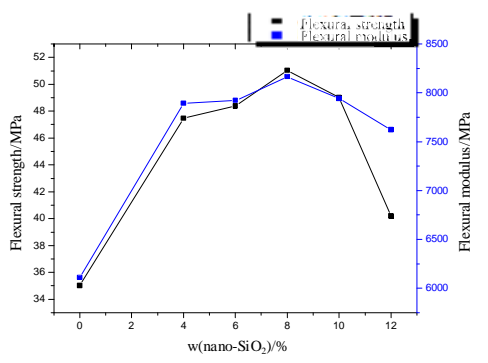

Fig. 2 Effect of nano $\mathrm{SiO}_{2}$ content on bending strength and bending modulus of composites

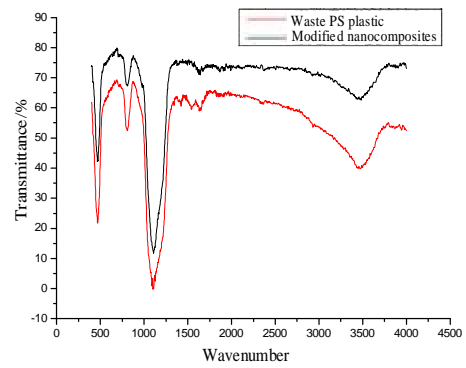

Fig.4 The FT-IR of $\mathrm{SiO}_{2}$ composites (A3) and waste polystyrene

Scanning electron microscope (SEM) analysis of modified nanocomposites

Fig.5 is a scanning electron micrograph of scrap polystyrene and impact sections with different amounts of $\mathrm{SiO}_{2}$ composites, respectively. It can be observed from the Fig.5, the more nano-SiO 2 is added, the higher the degree of the cross-section is, and the more nano- $\mathrm{SiO}_{2}$ is attached to the surface of the matrix. The section shows a rich layer of honeycomb, microfiber structure. A large number of fine nano- $\mathrm{SiO}_{2}$ particles are attached to the polyethylene resin, which is due to the injection process in the addition of plasticizers and lubricants, both of the nanoparticles can be evenly dispersed in the plastic matrix, so that nanoparticles can better prevent the expansion and extension of microcracks, where these microcracks absorb more energy, thereby improving the fracture toughness of composite materials and enhancing the toughness of composite materials.

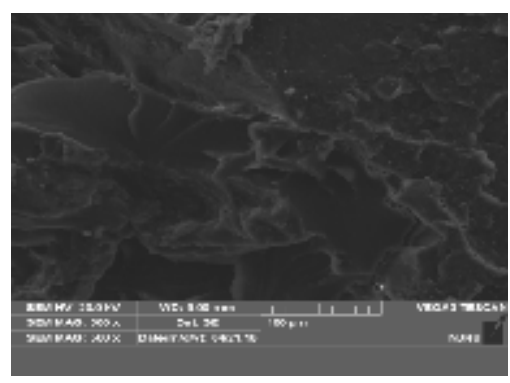

(a) sample A3

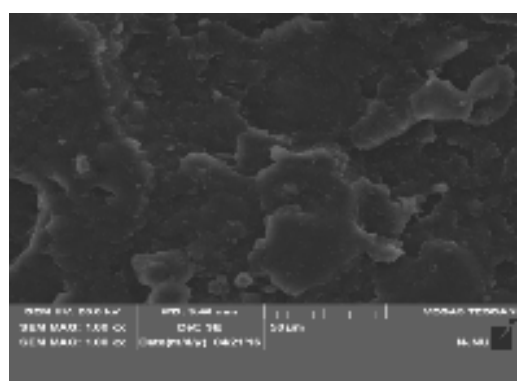

(b) sample A5

Fig.5 The SEM result of modified nanocomposites with sample

X-ray diffraction (XRD) results of modified nanocomposites 
Fig.6 plots the XRD patterns of waste PS plastic, and the XRD diagrams of the modified nanocomposites under 8\% nano- $\mathrm{SiO}_{2}$ composites. From Fig.6 (a), it can be observed that the sharp crystal peak appears when $2 \theta=21.65$, where the crystal spacing is 121.32 . From Fig.6 (b), it shows that when $2 \theta=21.45$ appears sharp crystal peak, interplanar spacing of 128.31 . It can be seen from the figure that the diffraction peaks of $8 \%$ nano- $\mathrm{SiO}_{2}$ composites are broadened and the crystallinity is lower than that of the used polystyrene, indicating that the modification is successful and there are many small particles distributed evenly on the composite material. These small particles are the nano- $\mathrm{SiO}_{2}$ attached to the waste polystyrene. The XRD diffraction curve of waste polystyrene has a wide main peak at $18^{\circ}$, and the nanocomposites show three peaks around $18^{\circ}$, which means that the synthesis of nanocomposites is very good.

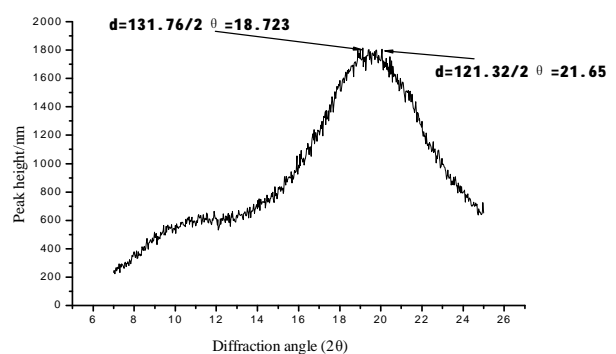

(a) A: waste PS plastic

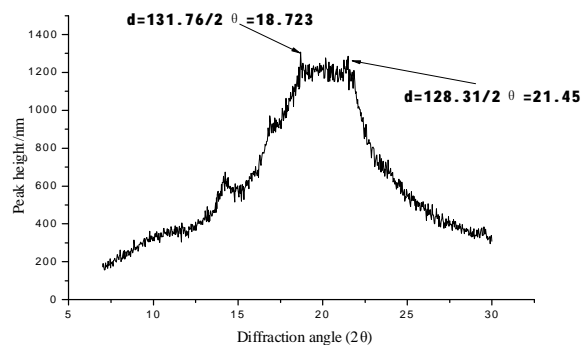

(b) A3: modified nanocomposites

Fig.6 The XRD patterns of waste PS plastic and modified nanocomposites

Thermogravimetric-differential thermal analysis (TG-DTA) of modified nanocomposites

Fig. 7 shows the thermal difference and thermogravimetry with $8 \% \mathrm{SiO}_{2}$ composite materials (A3) and waste polystyrene (A) at a temperature range of $0{ }^{\circ} \mathrm{C} \sim 700{ }^{\circ} \mathrm{C}$, respectively. For the $8 \% \mathrm{SiO}_{2}$ composite, the DTA curve in Fig.7 (a) shows a number of endothermic and exothermic peaks. The endothermic peaks are significant at $135^{\circ} \mathrm{C}, 400{ }^{\circ} \mathrm{C}$ and $450^{\circ} \mathrm{C}$, and the exothermic peak is from $500^{\circ} \mathrm{C} \sim 600^{\circ} \mathrm{C}$, where there is no mass change indicating that the composite grains tend to be ordered and the crystal form tends to be complete. Compared with the waste polystyrene, the DTA curve with $8 \% \mathrm{SiO}_{2}$ composite has better regularity.

From the thermogravimetry curve in Fig.7 (b), the $8 \% \mathrm{SiO}_{2}$ composite material is fairly stable by heating. The decomposition initiation temperature was $20^{\circ} \mathrm{C}$ and the termination temperature was $490{ }^{\circ} \mathrm{C}$. Before $250{ }^{\circ} \mathrm{C}$ there are only a small amount of weight loss and very few release of volatile matter, which may be due to the characteristics of plastic degradation reaction or the loss of water. The weight loss becomes obvious after $300{ }^{\circ} \mathrm{C}$, and the composite material is completely decomposed into volatile substances when the temperature keeps increasing. Compared with the weight loss of waste polystyrene plastic, the decomposition temperature of $8 \% \mathrm{SiO}_{2}$ composite material is lower, and its weight loss is $27 \%$ higher, i.e., the decomposition of $8 \% \mathrm{SiO}_{2}$ composite material is more thorough.

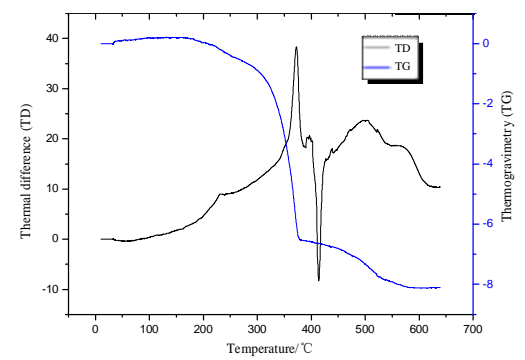

(a) A: waste PS plastic

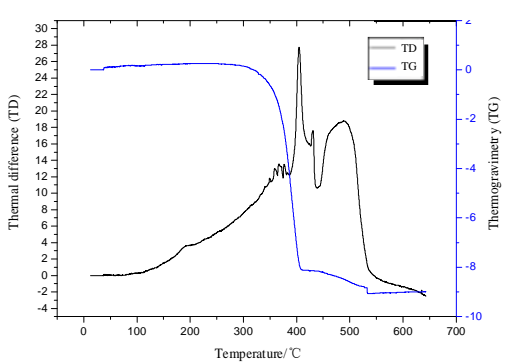

(b) A3: modified nanocomposites

Fig.7 The TG-DTA of waste PS plastic and modified nanocomposites

\section{Conclusions}

After nano- $\mathrm{SiO}_{2}$ is treated by silane coupling agent, the dispersion of nano- $\mathrm{SiO}_{2}$ in the composite material is more uniform. The modified SBS increases the toughness of nanocomposites. Through tests and analysis on stretching, shock and bending properties of polystyrene/nano-SiO 2 composites, it 
was found that when adding 64\% of spent polystyrene, $8 \%$ nano-SiO $2,10 \% \mathrm{SBS}$ rubber, $10.8 \%$ plasticizer, $0.2 \%$ stabilizer, $1 \%$ lubricant paraffin, $1 \%$ crosslinking agent DCP, and $5 \%$ colorant carbon black, the tensile strength of nanocomposites is $22.52 \mathrm{MPa}$, the elongation at break is $4.23 \%$, the impact strength is $18.33 \mathrm{~kJ} / \mathrm{m}^{2}$, the bending strength of $51.03 \mathrm{MPa}$, and the bending modulus of 8164.2 MPa.

After the addition of nano-inorganic material and organic rubbers in the waste polystyrene, there is an interaction in the matrix, where the nano-inorganic materials lead to decreased toughness and increased strength, while the organic rubber makes the toughness increase and the strength decrease. The amount of these two kinds of material is the main factor to change the performance of the composite. The differential thermal analysis shows that the thermal stability of nanocomposites is much higher than that of waste polystyrene. In addition, by comparing the infrared spectra of nanocomposites and waste polystyrene, it shows that $\mathrm{Si}-\mathrm{O}$ groups appear on the infrared spectrum of nanocomposites, which indicates that nano- $\mathrm{SiO}_{2}$ is grafted on nanocomposites.

\section{Acknowledgements}

Corresponding author: Li Dao-hua. This work was financially Supported by Patent Project of Science \& Technology Department in Neijiang Normal University (P016062) ; "Basic Chemistry Teaching Team"- Undergraduate Teaching Project by Neijiang Normal University (〔2015〕 96); Students Innovation and Entrepreneurship Training Program in Neijiang Normal University (X201635, X201633), and Major Project of Science \& Technology Department in SiChuan Province(2016JY0168).

\section{References}

[1] J. Liu, M. Xu, and B. Li. Hydrophobic modification of ammonium polyphosphate and its application in flame retardant polypropylene composites. Chemical Journal of Chinese Universities, 2015, 36(6), 1228-1235.

[2] M. S. Hamzah, I. N. Hidayah, and M. Mariatti. Dielectric and thermal properties of flame retardant fillers in polypropylene/ethylene propylene diene monomer composites. Journal of Reinforced Plastics \& Composites, 2014, 33(21), 1931-1940.

[3] M. D. Beg, S. Samahani and M. F. Mina. Simultaneous effects of coupling agent and flame retardant on empty fruit bunch fiber/polypropylene composites. Journal of Reinforced Plastics \& Composites, 2013, 32(17), 1268-1284.

[4] A. Elshad, J. Anupam, and W.Wenbo. Enlargement of halloysite clay nanotube lumen by selective etching of aluminum oxide. Acs Nano, 2013, 6(8), 7216-7226.

[5] J. Z. Liang, B. Zhu and W. Y. Ma. Morphology and mechanical properties of PP/POE/Nano$\mathrm{CaCO}_{3}$ composites. Polymer Composites, 2016, 37(2), 539-546.

[6] D. L. Chen and H. M. Yang. Polypropylene/combinational inorganic filler micro/nanocomposites: synergistic effect of micro-/nanoscale combinational inorganic fillers on their mechanical properties. Journal of Journal of Applied Polymer Science, 2012, 115(1), 624-634.

[7] M. Rong, M. Zhang and Y. Zheng. Improvement of tensile properties of nano-SiO$/ 2 / \mathrm{PP}$ composites in relation to percolation mechanism. Polymer, 2011, 42(7), 3301-3304.

[8] H. Ding and S. C. Lu. Surface modification of wollastonite by the mechano-activated method and its properties. International Journal of Minerals, Metallurgy and Materials, 2013, 18(1), 83-88.

[9] N. Sarier and O. Emel. Organic modification of montmorillonite with low molecular weight polyethylene glycols and its use in polyurethane nanocomposite foams. Thermochimica Acta, 2013, 510(1-2), 113-121.

[10] Z. J. Zhang, D. W and H. P. Xing. A new grafting monomer for synthesizing long chain branched polypropylene through melt radical reaction. Polymer, 2012, 53, 121-129. 